\title{
Avaliação e melhoria no processo de injeção de PEAD
}

\author{
G.CORRÊA ${ }^{1}$ e P. J. MELO ${ }^{1}$ \\ ${ }^{1}$ Universidade Federal do Rio Grande do Sul, Departamento de Engenharia Química \\ E-mail: guilherme.correa95@gmail.com
}

RESUMO - O processo de injeção de polímeros é um dos principais métodos utilizados na produção de peças e componentes industriais para eletrodomésticos, eletroeletrônica, indústrias automotivas e de calçados. Ele é realizado em três etapas sucessivas: aquecimento do material polimérico a uma temperatura superior ao seu ponto de fusão, injeção do material fundido em um molde metálico e resfriamento das peças injetadas. A geometria das peças e o controle das etapas do processo são fatores que influenciam na ocorrência de defeitos no produto final. Em peças volumosas verificam-se defeitos de retração da superfície ou a formação de bolhas no interior das mesmas. Neste trabalho, o problema de formação de bolhas em PEAD injetado foi estudo e reduzido, de $30 \%$ para menos de $3 \%$, através do controle das variáveis de solidificação tais como tempo e temperatura. As condições do processo de injeção e a umidade também podem contribuir para a redução da formação de bolhas.

\section{INTRODUÇÃO}

Materiais poliméricos são usados em praticamente todos os bens de consumo comercializados atualmente e o seu uso propiciou uma verdadeira revolução nas indústrias manufatureiras nos últimos 60 anos (Canevarolo, 2006). O incremento de consumo destes materiais nos últimos anos foi tão elevado que, em 1973, o volume mundial de produção de polímeros superou o de produção de aço, segundo (Mano e Mendes 2001) e (Wiebeck e Harada, 2005).

A preocupação com o descarte de grandes quantidades de termoplásticos, decorrente do elevado consumo de embalagens descartáveis, torna-se uma questão crucial a partir do ano 2000 quando a reciclagem em larga escala se consolida por imposição de legislações ambientais (Ana e Weibeck, 2011). A otimização dos processos de fabricação com reaproveitamentos e reciclagem contribuem para a redução de custos e também com a redução do descarte destes materiais.

O processo de produção por injeção gera um volume relativamente grande de aparas, rebarbas ou resíduos de usinagem das peças, que podem ser reaproveitados. A reciclagem de peças usadas é também uma prática difundida e recorrente na maioria das empresas produtoras de peças injetadas. $\mathrm{O}$ 
presente trabalho foi desenvolvido para uma empresa produtora de peças injetadas de Polietileno de Alta Densidade (PEAD) onde mais de 95\% da matéria prima usada no processo é oriunda de reaproveitamentos e material reciclado.

\section{CARACTERIZAÇÃO DO MATERIAL POR RIOS-X E ANÁLISE TÉRMICA}

\subsection{Análise de difração de Raios - X}

Esta análise mostra um espectro de intensidade (counts) x ângulo (two-theta), de difração de raios-X de ângulo rasante, que possibilita determinar os picos característicos do material cristalino analisado e sua cristalinidade. O espectro abaixo mostra dois picos característicos, com valores de $2 \theta$ em torno de 21,8 e 24,1 que são compatíveis com o material estudado, o PEAD. O índice de cristalinidade situa-se em torno de 73\% e os cristalitos tem tamanho médio de 200 Angstrons.

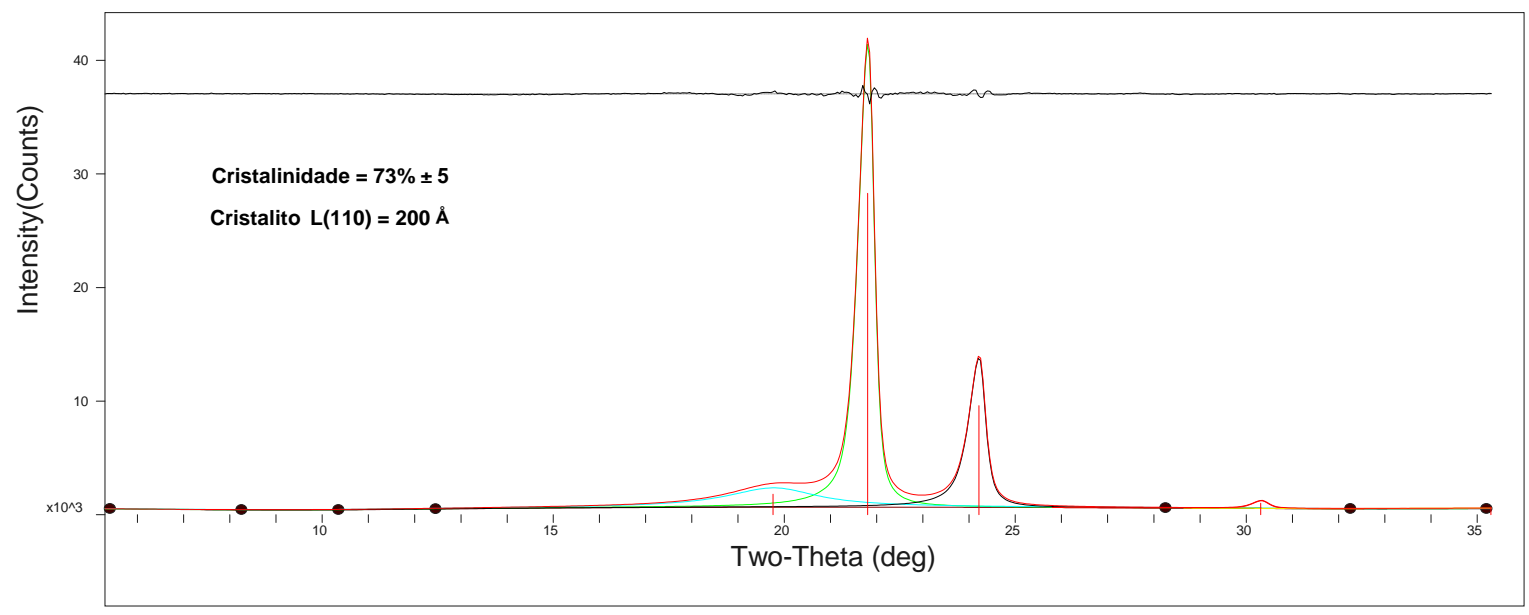

Figura 1 - Espectro de difração de raio-X de ângulo rasante, com radiação Ka Cu.

\subsection{DSC (Differential Scanning Calorimetry, ou calorimetria exploratória diferencial)}

As análises de DSC mostram o fluxo de calor sobre a amostra ao longo de um intervalo de temperaturas percorrido pelo equipamento. Assim, transições exotérmicas aparecem para cima e transições endotérmicas aparecem para baixo, segundo Lucas et al (2001). No diagrama mostrado na figura 2, verifica-se que o material funde a $136^{\circ} \mathrm{C}$ e apresenta um índice de cristalinidade de $74 \%$, que 
são compatíveis com os resultados da análise de raios-X e também as propriedades do PEAD, que tem temperatura de fusão de $135^{\circ} \mathrm{C}$ e elevado índice de cristalinidade.

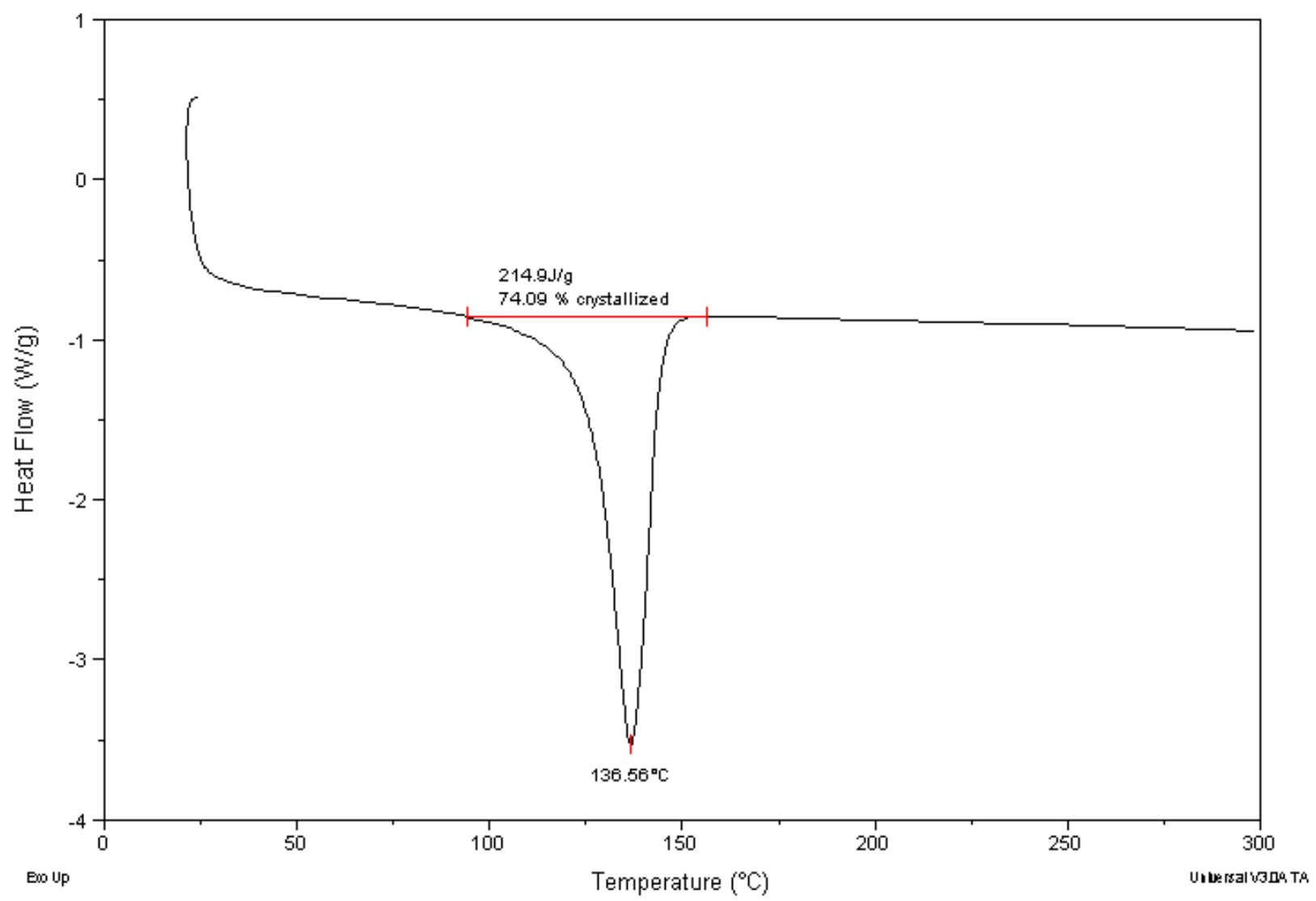

Figura 2 - Análise de DSC realizada em uma amostra do material usado como matéria prima do processo de injeção. Velocidade de varredura de $10^{\circ} \mathrm{C} / \mathrm{min}$.

\subsection{TGA (Thermogravimetric Analysis, ou Análise Termogravimétrica)}

As análises de TGA mostram a perda de massa das amostras em função da temperatura, como decorrência de volatilizações e degradações. Na figura 3, abaixo, se verifica uma degradação quase total da amostra entre $400^{\circ} \mathrm{C}$ e $500^{\circ} \mathrm{C}$ e um resíduo de $1,17 \%$ que se mantém em temperaturas superiores a $600^{\circ} \mathrm{C}$. 


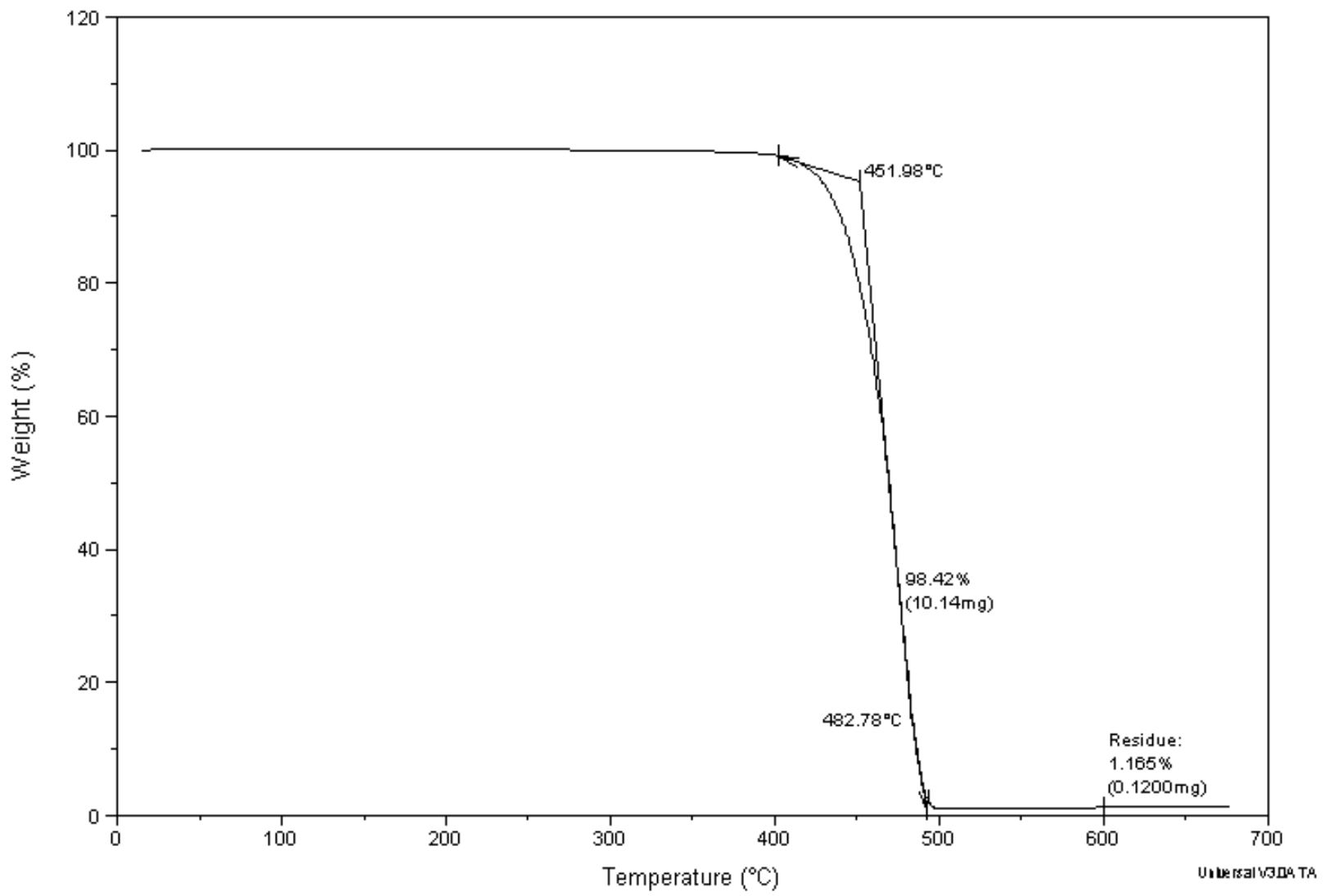

Figura 3 - Análise termogravimétrica de amostrado do material usado como matéria prima do processo de injeção. Velocidade de varredura de $10^{\circ} \mathrm{C} / \mathrm{min}$.

\section{RESULTADOS EXPERIMENTAIS}

Para verificar a ocorrência de defeitos nas peças injetadas foram coletadas amostras diárias das linhas de produção e, posteriormente, avaliadas quanto à formação de bolhas ou retração. Os resultados apresentados foram realizados ao longo de seis meses de acompanhamento da produção, nas condições de processamento que a empresa operava e após alteração das variáveis tempo e temperatura de solidificação.

\subsection{Imagens das amostras antes da alteração das variáveis do processo}

Aproximadamente 30\% das amostras avaliadas apresentaram a formação de bolhas no interior das peças injetadas. Este problema era decorrente, provavelmente, das condições inadequadas de temperatura e tempo de solidificação bem como da matéria prima utilizada sem o controle de umidade. A figura 4 mostra as fotografias da evolução da solidificação com o tempo e os tipos de 
defeitos que se formavam.

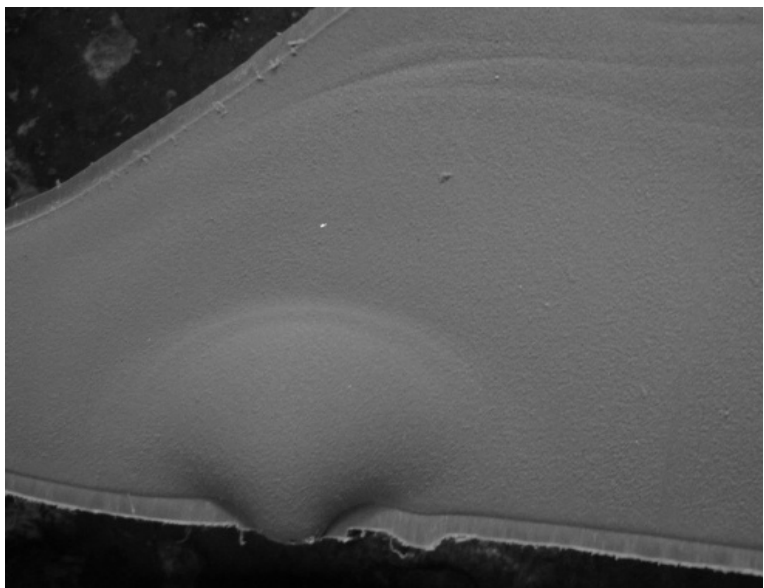

(a) Após a desmoldagem

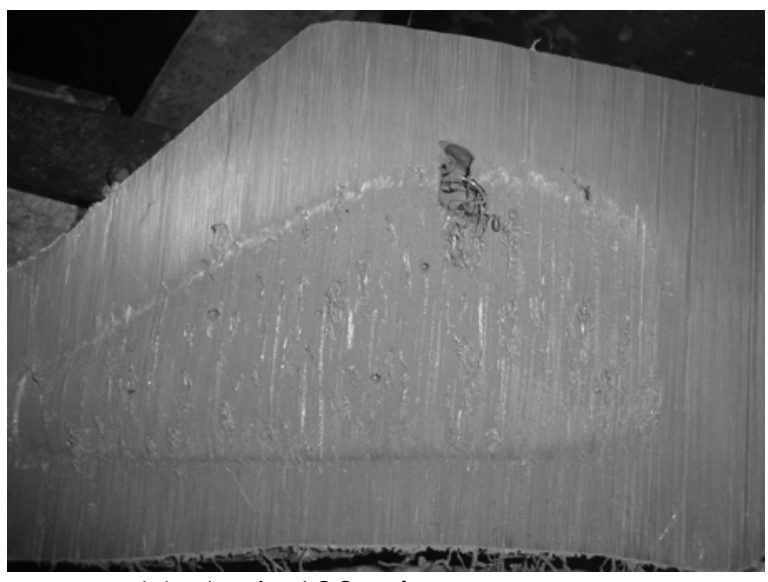

(c) Após 120 minutos ao ar

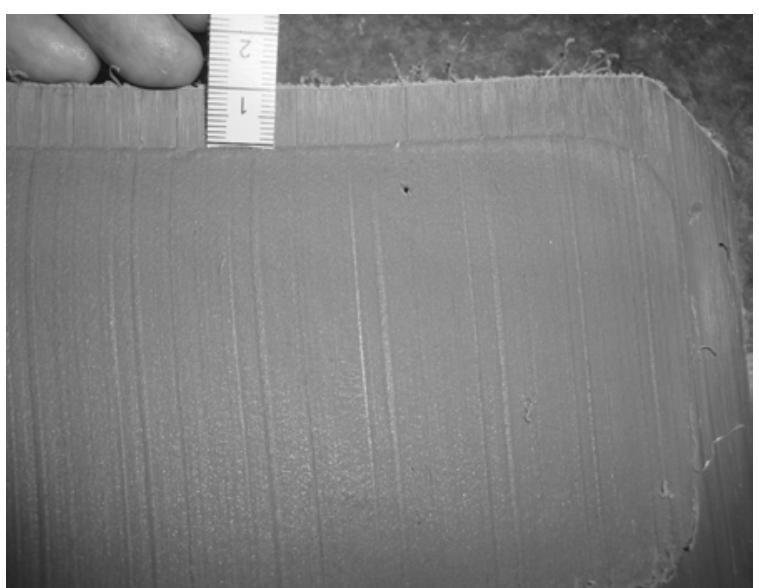

(b) Após 30 minutos de imersão em água

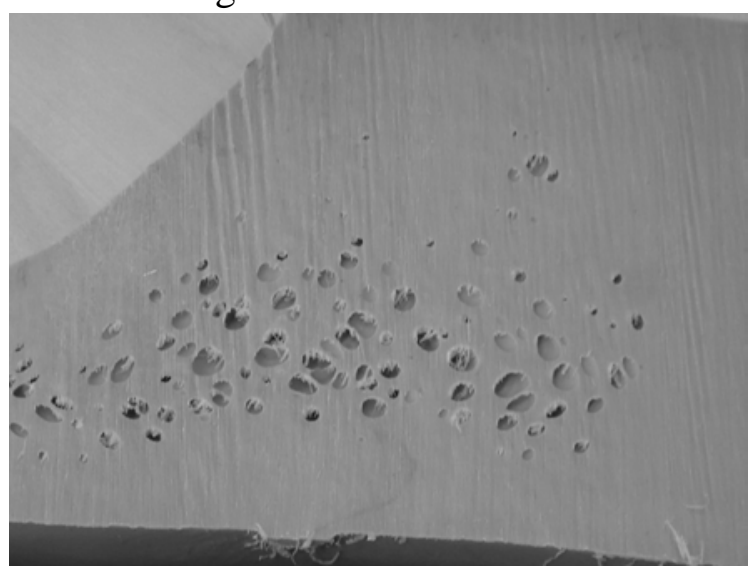

(d) Após 240 minutos ao ar

Figura 4 - fotografias mostrando a ocorrência de falhas ao longo do processo de solidificação das peças injetadas

Nestas imagens verifica-se o inicio da solidificação durante o resfriamento do molde, quando solidifica uma camada de aproximadamente $0,4 \mathrm{~cm}$ de espessura (4a). A pós a desmoldagem as peças ficam imersas em água durante 30 minutos e a espessura da camada solidificada aumenta para $1,0 \mathrm{~cm}$ (4b) e finalmente completa-se a solidificação ao ar ambiente, quando se verifica o surgimento das bolhas (4c e 4d) no interior das peças. 


\subsection{Imagens das amostras após a alteração das variáveis do processo}

Após a alteração das variáveis do processo de injeção tais como o controle da umidade da matéria prima, temperatura e tempo de solidificação das peças injetadas, houve uma redução significativa na ocorrência de defeitos, sendo que somente $3 \%$ das peças solidificadas, sob condições controladas, apresentaram a formação de bolhas no seu interior, como mostra a figura 5 . As condições de solidificação foram de 30 minutos de imersão em água à $70^{\circ} \mathrm{C}$ mais 240 minutos em estufa mantida a $100^{\circ} \mathrm{C}$.

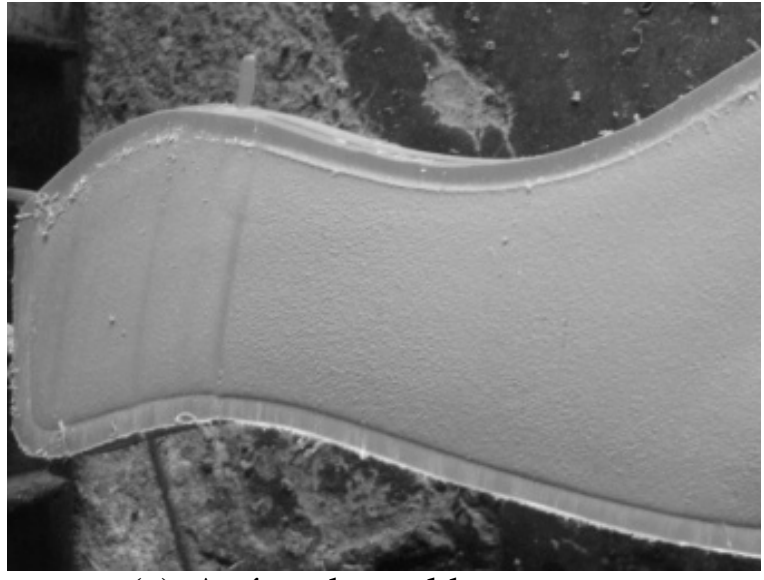

(a) Após a desmoldagem

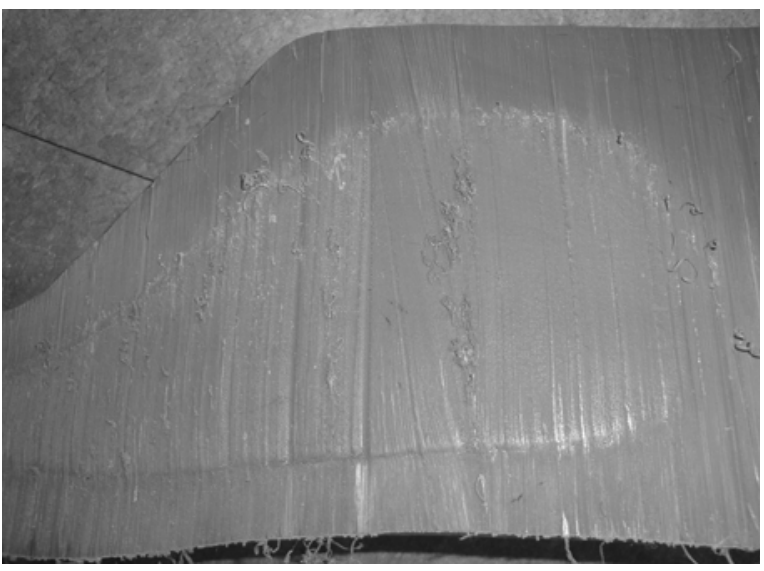

(c) Após 120 minutos ao ar, a $100^{\circ} \mathrm{C}$

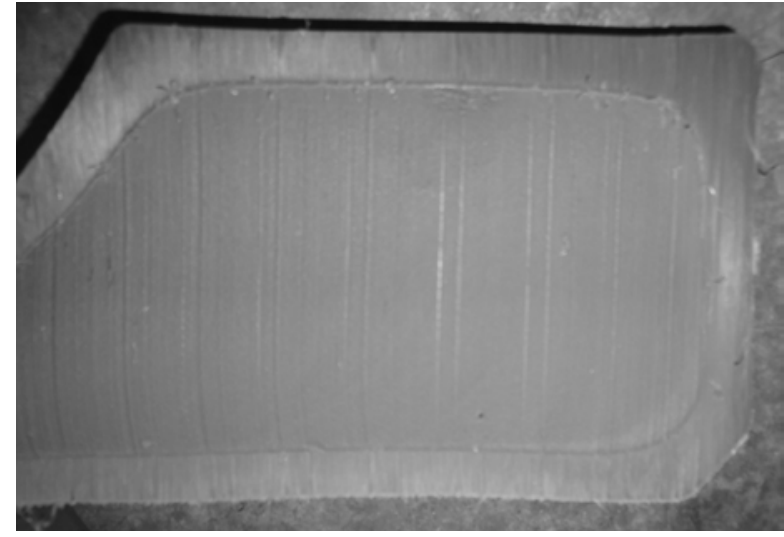

(b) Após 30 minutos de imersão em água, a $70^{\circ} \mathrm{C}$.

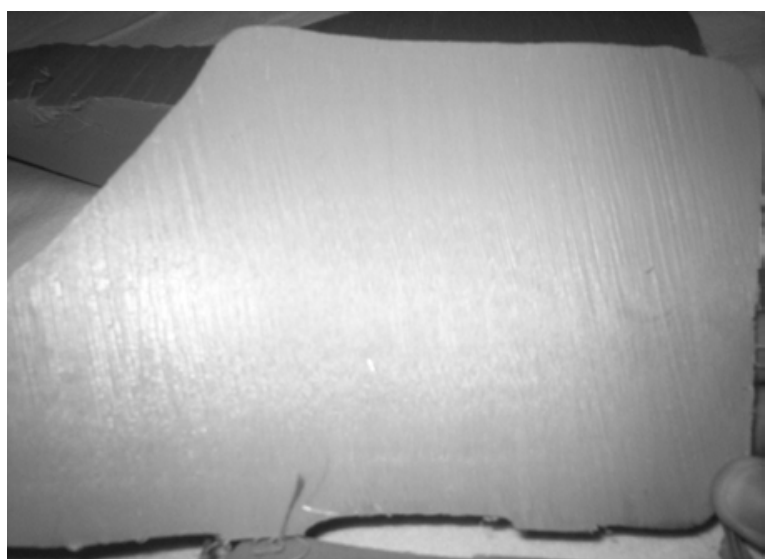

(d) Após 240 minutos ao ar, a $100^{\circ} \mathrm{C}$

Figura 5 - fotografias mostrando a redução na ocorrência de falhas após o processo de solidificação das peças injetadas 
A sequência de imagens mostradas na figura 5 evidencia que, com o controle da qualidade do material injetado e das condições de temperatura durante a solidificação, é possível se obter peças com baixo índice de defeitos.

\section{CONCLUSÕES}

Os resultados de difração de raios-X mostram que o material analisado tem um grau de cristalinidade superior a 70\% e picos de difração que coincide com os picos característicos do PEAD.

As análises de DSC e TGA evidenciam que as temperaturas de fusão e degradação das amostras analisadas são compatíveis com o PEAD e não evidencia a incorporação de outros materiais poliméricos oriundos da reciclagem. O resíduo da análise da TGA pode ser atribuído à incorporação de impurezas ou a presença de pigmentos inorgânicos.

Os dados experimentais, com o controle das variáveis do processo de solidificação, mostram que é possível reduzir a ocorrência de falhas como a formação de bolhas no interior das peças. O controle da temperatura em um patamar mais elevado mantém a flexibilidade da camada solidificada e com isto pode se evitar a formação de bolhas, que se formam devido à retração do material fundido no centra da peça, ao final da solidificação.

O controle da umidade do material injetado e a degaseificação, durante a injeção, também podem contribuir com a redução da formação de bolhas. Isto foi verificado em algumas peças que após a desmoldagem, já apresentavam defeitos.

A redução dos custos de produção, com a diminuição do reprocessamento de peças defeituosas, é evidente tendo em vista a redução significativa do tempo de uso das máquinas, uso de mão de obra e redução do consumo de energia.

Portanto, a instalação de uma estufa para o controle da temperatura das peças, após a esteira com água, poderá ser uma alternativa para eliminar (ou diminuir significativamente) a formação de falhas e reduzir os custos de produção. 


\section{REFERÊNCIAS}

CANEVAROLO, S. V. Ciência dos Polímeros. São Paulo: Editora Artliber-ABPol, 2006

LUCAS, E. F.; SOARES, B. G.; MONTEIRO, E. Caracterização de Polímeros. Determinação de Peso Molecular e Análise Térmica. Rio de Janeiro: Editora e-papers, 2001.

MANO, E.B.; MENDES, L. C. Polímeros como Materiais de Engenharia. Rio de Janeiro, São Paulo: Editora Edgard Blücher Ltda, 2000.

MANO, E.B.; MENDES, L. C. Introdução a Polímeros. Rio de Janeiro: Editora Edgard Blücher Ltda, 2001.

PIVA, A. M.; WIEBECK, H. Reciclagem do plástico. São Paulo: Editora Artliber, 2005

WIEBECK, H.; HARADA, J. Plásticos de Engenharia, Tecnologia e Aplicação. São Paulo: Editora Artliber-ABPol, 2005 